\title{
Density/area power-law models for separating multi-scale anomalies of ore and toxic elements in stream sediments in Gejiu mineral district, Yunnan Province, China
}

\author{
Q. Cheng ${ }^{1,2}$, Q. Xia ${ }^{1,3}$, W. Li ${ }^{4}$, S. Zhang ${ }^{5}$, Z. Chen ${ }^{1,3}$, R. Zuo ${ }^{1}$, and W. Wang ${ }^{2}$ \\ ${ }^{1}$ State Key Laboratory of Geological Processes and Mineral Resources, China University of Geosciences, Wuhan 430074, \\ Beijing 100087, China \\ ${ }^{2}$ Department of Earth and Space Engineering, Department of Geography, York University, Toronto, 4700 Keele Street, \\ M3J 1P3, Ontario, Canada \\ ${ }^{3}$ Faculty of Resources, China University of Geosciences, China \\ ${ }^{4}$ Yunnan Academy of Geological Survey, Kunming 650051, Yunnan, China \\ ${ }^{5}$ Institute of Resources and Environment, Shijianzhuang University of Economics, Shijiazhuang, China
}

Received: 1 April 2010 - Published in Biogeosciences Discuss.: 7 June 2010

Revised: 9 September 2010 - Accepted: 17 September 2010 - Published: 6 October 2010

\begin{abstract}
This contribution introduces a fractal filtering technique newly developed on the basis of a spectral energy density vs. area power-law model in the context of multifractal theory. It can be used to map anisotropic singularities of geochemical landscapes created from geochemical concentration values in various surface media such as soils, stream sediments, tills and water. A geochemical landscape can be converted into a Fourier domain in which the spectral energy density is plotted against the area (in wave number units), and the relationship between the spectrum energy density $(S)$ and the area $(A)$ enclosed by the above-threshold spectrum energy density can be fitted by power-law models. Mixed geochemical landscape patterns can be fitted with different S-A power-law models in the frequency domain. Fractal filters can be defined according to these different S-A models and used to decompose the geochemical patterns into components with different self-similarities. The fractal filtering method was applied to a geochemical dataset from 7,349 stream sediment samples collected from Gejiu mineral district, which is famous for its word-class tin and copper production. Anomalies in three different scales were decomposed from total values of the trace elements $\mathrm{As}, \mathrm{Sn}, \mathrm{Cu}$, $\mathrm{Zn}, \mathrm{Pb}$, and $\mathrm{Cd}$. These anomalies generally correspond to various geological features and geological processes such as sedimentary rocks, intrusions, fault intersections and mineralization.
\end{abstract}

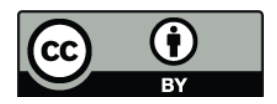

Correspondence to: Q. Cheng (qiuming@yorku.ca)

\section{Introduction}

Toxic elements such as arsenic occur naturally in surface media such as soils, water, and sediments, in part because of the weathering of rocks and ores that contain elevated concentrations of ore and toxic elements. There are many types of hydrothermal deposits that contain minerals such as arsenopyrite with high levels of arsenic and other toxic elements, including gold deposits, $\mathrm{Sn}$ deposits and $\mathrm{Pb} / \mathrm{Zn}$ deposits. Due to high concentrations of these elements in ores and country rocks, secondary weathering processes and human activities such as mining can cause dispersion of these elements in surface media. Cases of contamination have been reported worldwide, for example, arsenic contamination at the Mole River mine, northern New South Wales (Ashley and Lottermoser, 1999), arsenic contamination of Bangladesh paddy field soils and its association with arsenic consumption via rice (Meharg and Maziburrahman, 2003), sediment contamination by arsenic in parts of central-east India (Pandey et al., 2004) and contamination by arsenic and other elements of soil, plants, water and sediment in the vicinity of the Dalsung $\mathrm{Cu}-\mathrm{W}$ mine in Korea (Jung et al., 2002). Arsenic contamination related to mining and geology has also been actively studied in China. For example, studies have been conducted to assess heavy metal contamination in potatoes and peas in tin tailings in Gejiu mine (Gan et al., 2008), and arsenic contamination in stream sediments in Gejiu was also investigated (Zhou et al., 2006). The above two groups both reported significant arsenic contamination in the Gejiu area caused by the Sn mines and the long history of mining activity in the

Published by Copernicus Publications on behalf of the European Geosciences Union. 
area. It has been proven that arsenic contamination of soil, water and air can cause various health problems such as lung cancer. It was reported that in Gejiu city, $0.27 \%$ of the population is detected as having lung cancer each year, which is the highest lung cancer death rate of any city in China (Xie et al., 2000). To understand the spatial distribution of arsenic in surface media and to identify the various main sources of arsenic contamination are therefore critical issues both for environmental management and environmental remediation. To identify anomalous areas of these types of toxic contamination in association with mineralization and mining is an interesting subject attracting a great deal of attention from the ore geology and environmental geosciences community. To separate the influence of the natural process of mineralization from that of human mining activities is a critical task for environmental and mineral resource assessments. Due to the superimposed and complex processes involved in the formation of element concentrations in the secondary media, it is a challenge to fully understand the processes and the properties of their distribution. For example, various cascade geo-processes and bio-processes can cause singular distributions of element concentrations in primary and second media. This paper investigates the scaling properties of toxic elements in stream sediments by identifying components of anomalies that can be isolated to reveal the various causes of elevated toxic element concentrations in surface media

\section{Study area and materials}

\subsection{Study area}

The area chosen for the case study is Gejiu district, a wordclass tin production region that is located along the suture zone of the Indian and Eurasian plates on the southwestern edge of the China sub-plate, approximately $200 \mathrm{~km}$ south of the city of Kunming, capital of Yunnan Province. The mining of, exploration for and utilization of tin resources play an important role in economic development in both Gejiu city and Yunaan province. The tin resources in Gejiu are important for both the international and domestic non-ferrous metals industries. However, there is a current shortage of Gejiu tin resources because the tin reservoir has been mined for several decades. Therefore, mineral exploration in the deeper and peripheral spaces has become a top priority in Gejiu district. Contamination by toxic elements caused by natural mineralization processes and the mining activity has also become a critical issue for the sustainable development of the region.

To assess toxic element contamination in surface media and implement environment remediation, one needs to understand the sources of the contamination and their spatial distribution. These are the main objectives of the current study.

\subsection{Materials and data}

The dataset used in this paper comprises (1) a detailed 1:200 000 scale geological map (2) geochemical data regarding $\mathrm{As}, \mathrm{Cd}, \mathrm{Cu}, \mathrm{Pb}, \mathrm{Zn}$ and $\mathrm{Sn}$ derived from 7,349 stream sediment samples, and (3) Sn mineral distribution information that includes geographic coordinates and other geological attributes. The geochemical data were the main dataset for the study. The area chosen for this study was covered by about 7,349 evenly distributed stream sediment samples, each covering a $2 \mathrm{~km} \times 2 \mathrm{~km}\left(4 \mathrm{~km}^{2}\right)$ area. These samples were collected and analyzed by the Chinese National Geochemical Mapping Project as part of the Regional Geochemistry National Reconnaissance (RGNR) Project, which was initiated in 1979. Between 1979 and 1997, the project has generated a vast quantity of geochemical data covering a total area of 5.17 million $\mathrm{km}^{2}$ in China (Xie et al., 1997). For each sample, the concentrations of 39 geochemical elements and 7 compounds were measured at equally spaced $2-\mathrm{km}$ intervals throughout the study area. The data used in the current paper are geochemical concentration values in unit of ppm of $\mathrm{As}, \mathrm{Sn}, \mathrm{Cd}, \mathrm{Cu}, \mathrm{Pb}$, and $\mathrm{Zn}$ trace elements. Further details about the processes involved in sampling and analyzing the stream sediment geochemical data can be found in Xie et al. (1997). The trace elements and their associations with $\mathrm{Sn}$ mineralization in the area were previously studied (Cheng, 2007; Cheng and Agterberg, 2009; Cheng et al., 2009).

\subsection{Geology of Gejiu district}

The geological units of Gejiu district are hosted by a sequence of Paleozoic to Mesozoic sedimentary rocks (the Gejiu formation and other formations) and igneous rocks including Paleozoic volcanic rocks and Mesozoic intrusive rocks (Fig. 1). The Gejiu Batholith, which is located in the center of Gejiu district, is key factor for Sn mineralization. The Gejiu formation is hosted by limestone with minor dolomites. The Gejiu formation is the main country rock hosting most of the discovered Sn deposits. Carbonate minerals such as calcites and dolomites are the dominant minerals found in the ore tailings (Gan et al., 2008). The main faults and folds in the central part of the study area have $\mathrm{N}-\mathrm{S}$ and $\mathrm{E}-\mathrm{W}$ orientations, and the main faults and folds in the other parts of the study area are NE-SW, NW-SE and E-W trending. Intersections of the three groups of fault systems are commonly seen in the area. These fault systems control the general configuration of the mineralization and distribution of ore bodies in this area. The main trend of the mineralization is in the NNE-SSW orientation in the central area, but the ore fields are concentrated along the intersections of NNE-SSW and E-W faults. The mineral assemblages associated with the mineralization include pyrrhotite, pyrites, cassiterite, galena, sphalerite and arsenopyrite. The Sn ores also contain high concentration values of the trace elements $\mathrm{Pb}, \mathrm{Zn}, \mathrm{Cu}, \mathrm{As}, \mathrm{Sb}, \mathrm{Bi}, \mathrm{Au}$, and $\mathrm{Ag}$. More comprehensive 


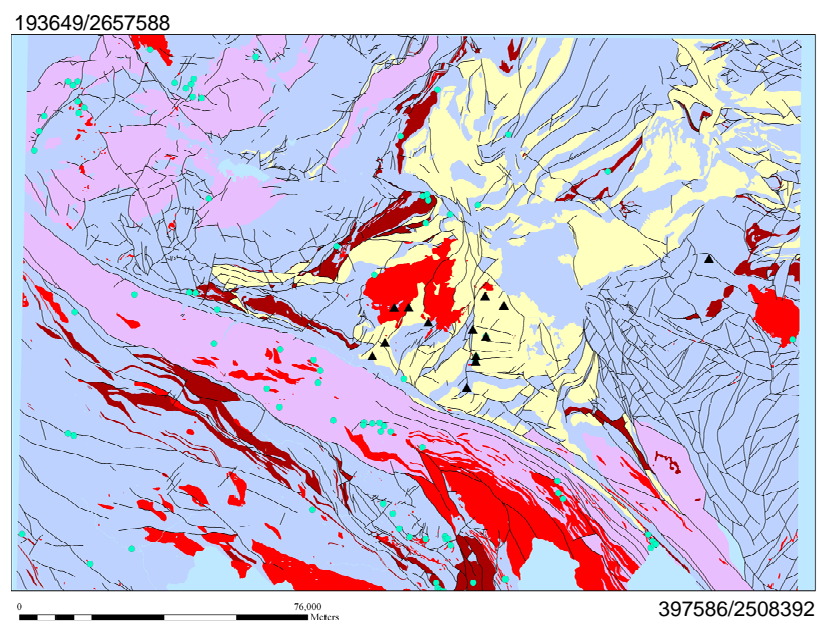

Fig. 1. Simplified geology of the study area derived from four 1:200 000 scale maps (Southwestern Geological Exploration Team, 1984). Pink represents Proterozoic metamorphic rocks, yellow is for the Gejiu Formation of Paleozoic carbonate sedimentary rocks, grey is for other sedimentary rocks, dark red is for mafic igneous rocks including basalts, red is for felsic intrusive rocks, solid lines are for faults systems and the two types of point symbols, black triangles and green circles, respectively represent $\mathrm{Sn}$ and $\mathrm{Cu}$ mineral deposits and occurrences.

descriptions of the geology, geochemistry and mineralogy of the area can be found in Qing et al. (2004) and Yu et al. (1988).

\section{Methodology}

A fractal filtering method developed on the basis of the generalized self-similarity principle (Cheng et al., 1999; Cheng, 2004) was used to separate the mixing patterns of As in the area.

\subsection{A generalized self-similarity and spectrum density/area power-law model}

Scale invariance, including self-similarity (or isotropic), selfaffinity (or stratification) and generalized self-similarity (or anisotropy) is a common property of spatial patterns generated from various geological processes and events. Fractal and multifractal models have been applied in various fields as powerful tools to characterize the scale invariance of geoprocesses and geo-events. Multiple successes have been reported with the application of fractal and multifractals in the context of geocomplexity (Lovejoy et al., 2009). While most of the fractal models were used to deal with isotropic scale invariance, several models have been investigated for modeling anisotropic scale invariance. For example, a new formalism of generalized scale invariance (GSI) was proposed and utilized by Schertzer and Lovejoy $(1985,1987)$ to model scale invariance more generally. This formalism states that large and small scales of geo-fields can be related by general scale-transform operations without introducing a characteristic size. Various models were developed to simulate geo-fields with anisotropic scale invariance (Lovejoy and Schertzer, 2007; Lovejoy et al., 2009). A different model was proposed on the basis of extreme value distributions of 2-D multifractal fields stating that the concentration value $(C)$ and the area enclosed by the cutoff concentration value $(A[>C])$ follow a power-law relation (Cheng et al., 1994).

$A[>C] \propto C^{-\beta}$

This concentration-area model (C-A model) idea was further extended to characterize the spectral energy density/area relation in frequency domains (Cheng et al., 1999). A powerlaw was proposed to relate the spectral energy density $(S[\omega]$, where $\omega$ is wave number vector) to the area with threshold $S$ $(A[>S])$, and

$A[\geq S] \propto S^{-2 d / \beta}$

where $\alpha$ stands for "proportional to", $\beta$ is the anisotropic scaling exponent, and $\mathrm{d}$ is a parameter representing degree of overall contraction (Cheng et al., 1999; Cheng, 2004). Since the shape of $A$ involved in these models (C-A and S-A) at different concentrations $(C)$ or spectral energy densities $(S)$ can be any self-similarly shaped contour, these self-similar contours characterize the anisotropic scale invariance of the density distribution. Thus, the exponent of the power-law relation becomes an essential index that characterizes generalized self-similarity, implying that a geo-field shows diversity in the spatial domain and depicting self-similarity in a special domain such as a Fourier domain (Cheng 2004, 2005).

\subsection{Fractal filtering technique}

The fractal filtering technique was developed on the basis of the S-A power-law model by Cheng, Xu and Grunsky (1999) for decomposing mixing patterns into components according to distinct self-similarities identified in Fourier domains. According to the power-law relation between $S$ and $A$, when the data of $S$ and $A$ are plotted on a log-log plot, several straight-line segments can usually be fitted to the relation S-A. Each spectral energy density range within which $S$ and $A$ is fitted by a straight-line segment can be used to define a fractal filter. For example, if two straight-line segments are fitted to the data and these straight-lines yield the threshold $S_{0}$, then two filters can be defined as: $G_{B}(\omega)=1$ if $S(\omega)>S_{0}$, and if otherwise, $G_{B}(\omega)=0$; and as $G_{A}(\omega)=1$ if $S(\omega) \leq S_{0}$, and if otherwise, $G_{A}(\omega)=0$. From the definitions of $G_{A}(\omega)$ and $G_{B}(\omega)$, we can see that the shapes of the filters could be irregular depending on the complexity of the spectral energy density distribution. However, in general, the wave numbers $\omega$ in filter $G_{A}(\omega)$ are relatively larger than those in $G_{B}(\omega)$, implying that the frequency in $G_{A}(\omega)$ is relatively higher than that in $G_{B}(\omega)$. In this sense, $G_{A}(\omega)$ 
corresponds to a relatively high frequency component and $G_{B}(\omega)$ to a relatively low frequency component. However, one must keep in mind that the two filters are not sharply bounded either by frequency or by wave number. They are defined in such a way that the spectral energy density distributions on the two filters satisfy distinct power-laws or have different anisotropic scaling properties that, in a simple situation, may correspond to distinct (isotropic) self-similarities or self-affinities (stratification). Applying the inverse Fourier transformation with these two filters applied to the Fouriertransformed functions we get decomposed components in the space domain:

$\left.\left.\mathrm{T}_{B}=F^{-1}\left[F(\mathrm{~T}) \mathrm{G}_{\mathrm{B}}\right)\right], \mathrm{T}_{\mathrm{A}}=\mathrm{F}^{-1}\left[\mathrm{~F}(\mathrm{~T}) \mathrm{G}_{\mathrm{A}}\right)\right]$

where $F$ and $F^{-1}$ represent the Fourier and inverse Fourier transformations of a map T, respectively. From the property of the Fourier transformations, we can see that the total field $\mathrm{T}$ is decomposed into two components $\mathrm{T}_{A}$ and $\mathrm{T}_{B}$ with different frequency properties, $\mathrm{T}=\mathrm{T}_{A}+\mathrm{T}_{B}$. The frequencies of $\mathrm{T}_{A}$ and $\mathrm{T}_{B}$ may not be totally different but they must show distinct scaling properties in their spatial distribution as quantified by two distinct power-laws in the frequency domain. Depending upon the actual property of the spectral energy density distribution of the field, one may define two or three filters on the basis of the power-law relations of $S$ and $A$.

We know there are many different types of filtering techniques such as frequency - based high- low- and band-pass filters and wavelet filters. Most of these filters are involved filters defined with predetermined functions. The problem for these types of filters is how to decide the separation of low- and high-pass filters. In some cases these types of decisions are made arbitrarily. The method S-A introduced in the current paper involves separation of filters based on distinct self-similarities as defined using S-A plots. However, to empirically and systematically compare the results obtained by S-A method and many other filtering methods are still needed for a comprehensive evaluation of the effectiveness of S-A on filtering. This should be studied in our future research. This paper introduces a simple version of S-A so that it can be readily used in the field of soil imaging and non-linear imaging processing.

\section{Results and discussion}

The original geochemical data for $\mathrm{Sn}, \mathrm{As}, \mathrm{Cu}, \mathrm{Pb}, \mathrm{Zn}$ and $\mathrm{Cd}$ were converted into a grid with $2-\mathrm{km}$ intervals without interpolation. For example, the concentration distribution of the element As (Fig. 2) shows that the high values are mainly distributed in the central and upper parts of the study area where carbonate sedimentary rocks of the Gejiu formation and basalts are the dominate rock types. High anomalies of As are also found around the felsic intrusions and around several large tin deposits. The elevated values of $\mathrm{Sn}, \mathrm{Cu}, \mathrm{Zn}$,

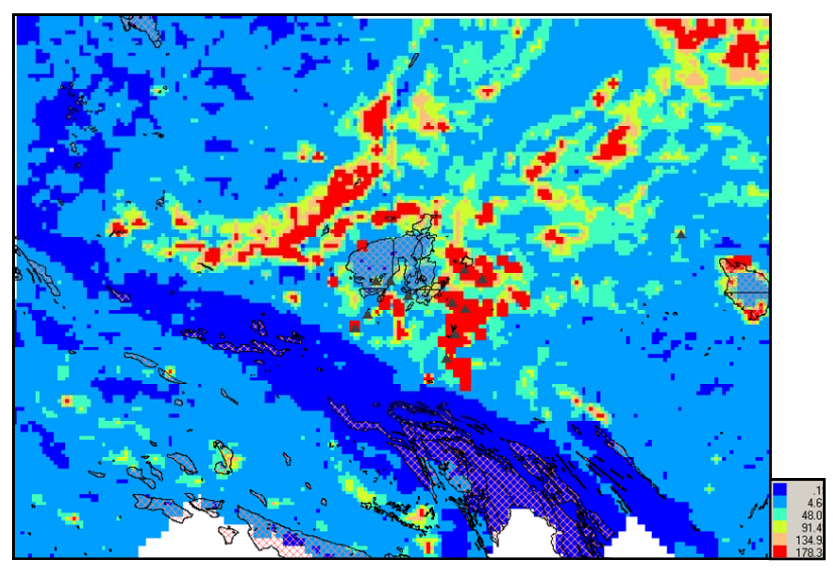

Fig. 2. A geochemical landscape created by As concentration values in ppm of stream sediment samples. The black polygons are mapped intrusions. The black triangles are tin mineral deposits.

$\mathrm{Pb}, \mathrm{Cd}$ and As are generally in agreement with the locations of known tin and copper mineral deposits (the results for the other elements are not shown here). The patterns of As in Fig. 2 represent the total values analyzed in the stream sediment samples and these values were caused by overlapping processes such as sedimentation, volcanic activity, igneous activity, faulting activity and mineralization. They can also be influenced by surface weather processes and human activities, among other things. Due to the different nature of these processes, the patterns related to these types of processes may be distinguishable according to various properties such as frequency distribution when the patterns treated as space series. It is its distinctive frequency distribution and scaling property that allow the S-A fractal filtering technique to separate patterns according to their distinct self-similarity observed from the spatial patterns in the frequency domain.

To apply the spectrum-area model (S-A) to the dataset, the landscape of As values (Fig. 2) was converted into the frequency domain by means of Fourier transformation. Two components: power spectrum density and phases, were obtained by Fourier transformation. On the power spectral energy plane, various thresholds of power spectral energy density were set and the areas enclosed with the thresholds were plotted on a log-log plot (Fig. 3a). A number of straight lines can be fitted to the data. How many straight lines to fit the data can be intuitively determined with several considerations: how good the fitting will be, how significant different between the slops of straight lines fitted to the data, and whether the results to be obtained with the filtering determined are physically meaningful, in other word, the results can be geologically interpreted. In the case study, three straight lines were fitted to the data using the least squares (LS) method. These three lines separate the values into three ranges, where the distinct scaling properties of the S-A relation are maintained in each. These three ranges of $S$ 

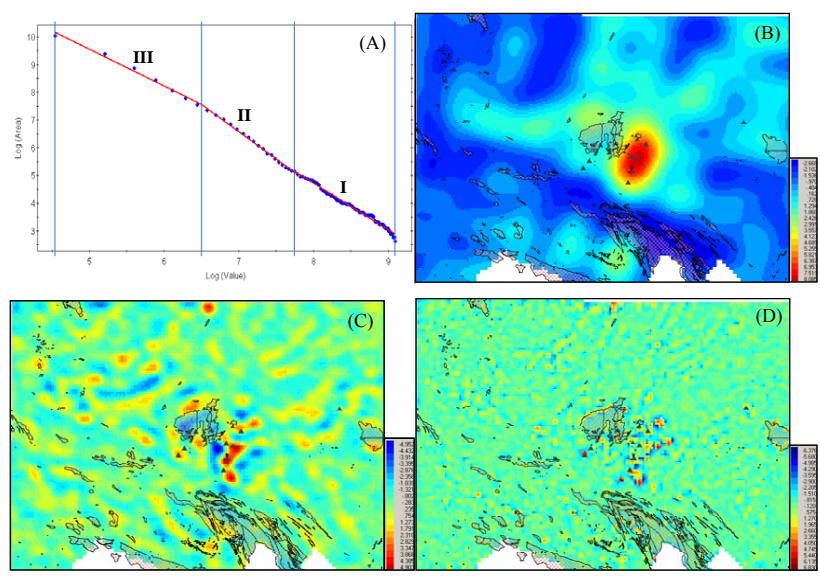

Fig. 3. (A) Plot showing the S-A relationship between the spectral energy density $(S)$ and area $(A)$. The dots are the calculated results and the three red lines labeled as I, II, and III were fitted by the LS method. The logarithmic transformations are base ten. (BD) Decomposed background, anomalous and noise components of As using filters I, II and III, respectively. The black polygons are mapped intrusions. The black triangles are tin mineral deposits.

are separated by two cutoff values, $S=662.95$ and 2295.79 . The slopes of these three straight lines are significantly different, for example, $-1.33,-1.97,-1.68$, and the intercepts of the three straight-lines are $16.21,20.34$, and 18.15 , respectively. The standard errors related to these three linear fits are $0.007,0.002$ and 0.004 , respectively. These standard errors (values $<0.01$ ) indicate the fittings of all three straight lines are statistically significant. The cutoff values $S=662.95$ and 2295.79 were used to define three filters: one consists of wave numbers with $S \leq 662.95$ as the noise filter, $662.95<S \leq 2295.79$ as the anomaly filter and wave numbers with $S>2295.79$ as the background filter. The shapes of the three filters are irregular and maintain the anisotropic properties and spatial structure of the geochemical pattern. Within these three filters $S$ and $A$ follow three distinct powerlaw relations each with its own exponent, implying that the signals in these ranges are self-similar.

Applying the three filters with ranges of $S$ defined as I, II and III in Fig. 3a to the Fourier-transformed functions and then converting them back to the spatial domain, three decomposed maps were created and are shown in Figs. 3b, c and $\mathrm{d}$. Figure $3 \mathrm{~b}$ represents the background component of the geochemical landscape, which generally coincides with the Gejiu formation except for an anomaly located east of the Gejiu Batholite coinciding with known mineral deposits. It was proposed that these areas are underlined by buried Gejiu Batholite (Cheng et al., 2009). However, Fig. 3c shows that local As anomalies are distributed not only in the central region but also in other areas. The anomalous areas are spatially in good agreement with the locations of known mineral deposits, along faults or around fault intersections. Figure $3 \mathrm{~d}$

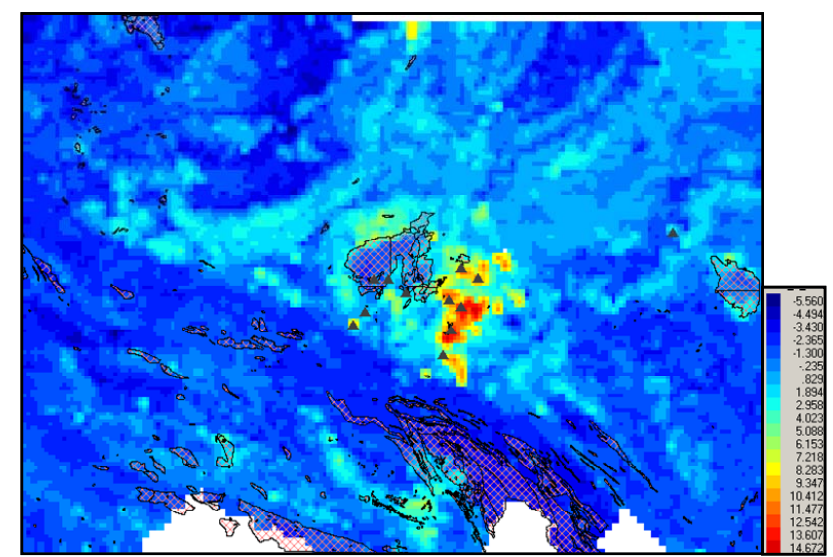

Fig. 4. Distribution of first principal component scores calculated using principal component analysis with a correlation coefficient matrix for the log-transformed values of the elements $\mathrm{Sn}, \mathrm{As}, \mathrm{Zn}$, $\mathrm{Pb}, \mathrm{Zn}$ and $\mathrm{Cd}$. The loadings of these elements are similar and the first component accounts for $67 \%$ of the variance of the total dataset. The black polygons are mapped intrusions. The black triangles are tin mineral deposits.

shows patterns generally of a random nature except for some locations with individually high values.

To further investigate the association of As and other relevant ore elements found in tin and copper mineral deposits, six maps were created for the elements $\mathrm{Sn}, \mathrm{As}, \mathrm{Pb}, \mathrm{Zn}, \mathrm{Cu}$ and $\mathrm{Cd}$ in the same way as the As map. These six maps were combined by means of principal component analysis with a correlation coefficient matrix model. More about the general use of principal component analysis (PCA) and some new extensions of PCA can be found in many references, such as Cheng et al. (2006). The first principal component reflects the combination of all six elements with evenly distributed positive loading. This indicates that the component represents the main elements associated with $\mathrm{Sn}$ and $\mathrm{Cu}$ mineralization. This component accounts for $67 \%$ of the variance of the entire dataset. The scores of the six elements on the first principal component were calculated and are shown in Fig. 4. The score patterns in Fig. 4 generally show high values in the area of the Gejiu formation and around the Gejiu Batholite and other felsic intrusions. Again, the patterns represent the overlapping contributions of various geological features and processes. In order to further decompose the score patterns on the basis of self-similarity using the S-A method, the score map was further converted into a frequency domain by means of Fourier transformation. The S-A plot is shown in Fig. 5a. The values of $S$ and $A$ generally show a descending trend. Three straight-line segments were fitted to the data by means of the LS method. Using processes similar to those used in Fig. 3a, three straight lines yield two cutoff values of $S=487.57$ and 2387.63. The slopes of these three straight lines are $-1.25,-1.88$, and -1.69 , and the intercepts are $15.80,19.69$, and 18.28. The standard errors related to these 

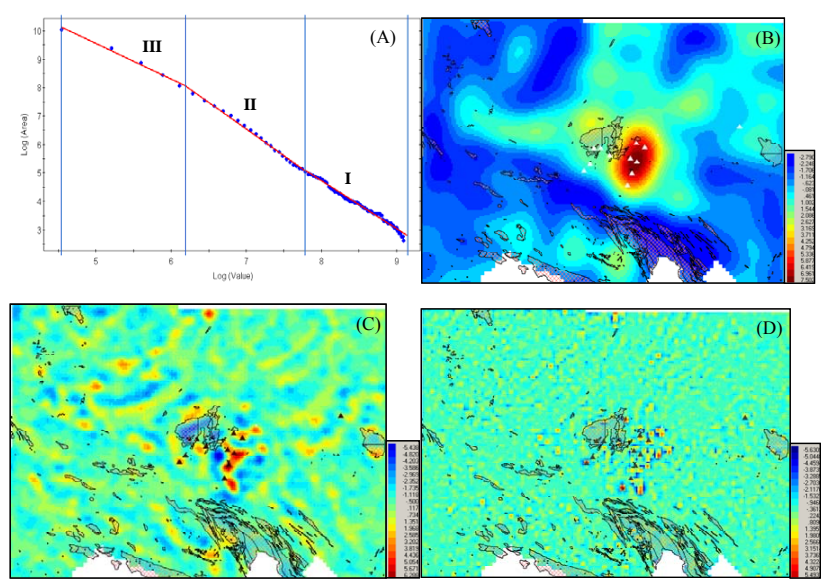

Fig. 5. (A) Plot showing the S-A relationship between the spectral energy density $(S)$ and area $(A)$. The dots are the calculated results and the three red lines labeled as I, II, and III were fitted by the LS method. The logarithmic transformations are base ten. (BD) Decomposed background, anomalous and noise components of As using filters I, II and III, respectively. The black polygons are mapped intrusions. The black triangles are tin mineral deposits.

three linear fits are $0.006,0.004$ and 0.005 , respectively. The cutoff values $S=487.57$ and 2387.63 were used to define three filters: one consists of wave numbers with $S \leq 487.57$ as the noise filter, $487.57<S \leq 2387.63$ as the anomaly filter and wave numbers with $S>2387.63$ as the background filter. Applying these three filters to the Fourier-transformed functions and then converting them back to the spatial domain generates the three decomposed maps: background, anomaly and high frequency (noise) maps as shown in Fig. 5b, c and d, respectively. The background map (Fig. 5b) shows the general trend with elevated values located in the areas around the Gejiu formation and basalts. This implies that the Gejiu formation must be favorable rock for Sn mineralization. In addition, a distinct anomaly is highlighted in the east Gejiu Batholite where igneous rocks are observed in drill halls and buried intrusions were inferred by processing geophysical data (Cheng et al., 2009). In this anomaly, most tin and copper mineral deposits are found. In Fig. 5c, the local anomalies appear as elongated or chain patterns. These linear anomalies are highly associated with either the known mineral deposits, faults or the intersections of fault systems, implying that these types of anomalies may indicate locations where mineralization occurred on the surface or at depth. These anomalies provide small target areas for further mineral exploration. It was reported that some new mineral deposits have been found in the areas identified by SA method (Li et al., 2006). Fig. 5d shows the high frequency component of the geochemical landscape, which mainly reflects random noise except some locations with individually high values. This small-scale highly noisy pattern may also be related to mine tailings and ore transportation in the area.
This case study, where we separated the geochemical landscape into various components on the basis of generalized self-similarities quantified in frequency domains, has demonstrated that the low-frequency background component is generally related to favorable rock types as well as the influence of intrusions, whereas the anomalies as intermediate frequency components are generally related to fault systems and intersections of faults, which are favorable areas for lactating mineral deposits. Most of the known large mineral deposits are located in these anomalous areas. The highfrequency component decomposed with the high-pass filter is generally random noise except some locations with individually high values that may be due to mining activities and tailing storage. It has been shown that the self-similarity property quantified by the S-A power-law model in a frequency domain can be used to decompose the total and often mixed geochemical patterns into separate components with distinct frequency distribution self-similarities that are related to various geological features and/or processes. This example has also demonstrated that igneous intrusions (such as the Gejiu and Rushan Batholiths), sedimentary rocks (Gejiu Formation) and various fault systems in the study area play important roles in controlling mineralization. The Gejiu formation of carbonates shows high concentrations of element associations and the igneous rocks intruded into the Gejiu formation caused large anomalies in their outer contact zones that provide a favorable background environment for mineralization. Fault activity and intersections of fault systems provide a favorable environment for local anomalies and for the occurrence of mineral deposits. Due to the dimensional distinction of these types of features and processes and their influences on the patterns of the geochemical landscape, it is possible to decompose the geochemical patterns according to the contributions of these features and processes.

\section{Conclusions}

A generalized self-similarity S-A model was successfully used to decompose the mixed geochemical landscapes caused by various scales of geological processes and features. The anomalies decomposed using the S-A model in the case study not only coincide with the locations of known mineral deposits, new anomalies delineated in other locations may be promising target areas for the discovery of new mineral deposits of the same type. Since the anomalies are delineated according to their self-similarity in the frequency domain, the size and intensity of these anomalies are not constant but follow the same self-similarity relation as in frequency domain. Therefore, the size and the number of anomalies may depict fractal properties that can be characterized by a fractal model. Since it often involves multiple ranges of energy power density $(S)$ in the process of defining filters, for example, in the case study used in the current paper, it involves three ranges of $S$ within each a power-law 
function is established between energy density $(S)$ and area $(A)$, these types of filters can be termed multifractal filters. The results obtained from this study also indicate that there are potential areas for the discovery of new mineral deposits. The favorable areas are those places with local geochemical anomalies and other geological factors including the Gejiu formation, intrusions and fault systems. Toxic elements and ore elements are closely associated in this area, which indicates a potential for toxic element contamination due both to natural processes and human activity. Although strategically planning for both resource utilization and environmental protection is challenging, our results indicate that such planning will be required in order to maintain sustainable development in the region.

Acknowledgements. Thanks A. M. Tarquis for her kind invitation to write this paper. The research was financially supported by a Distinguished Young Researcher Grant (40525009)", a Strategic Research Grant (40638041) awarded by the Natural Science Foundation of China, a High-Tech Research and Development Grant (2006AA06Z115, 2008AA121103) by the Ministry of Science and Technology of China and Grants from Ministry of Education of China (No. IRT0755 and No. 104244)

Edited by: A. M. Tarquis

\section{References}

Ashley, P. M. and Lottermoser, B. G.: Arsenic contamination at the Mole River mine, northern New South Wales, Aust. J. Earth Sci., 46, 861-874, 1999.

Cheng, Q: A new model for quantifying anisotropic scale invariance and for decomposition of mixing patterns, Math. Geol., 36, 345360, 2004

Cheng, Q.: Multifractal distribution of eigenvalues and eigenvectors from 2D multiplicative cascade multifractal fields, Math. Geol., 37, 915-927, 2005.

Cheng, Q.: Mapping singularities with stream sediment geochemical data for prediction of undiscovered mineral deposits in Gejiu, Yunnan Province, China, Ore Geol. Rev., 32, 314-324, 2007.

Cheng, Q. and Agterberg, F. P.: Singularity analysis of ore-mineral and toxic trace elements in stream sediments, Comput. Geosci., 35, 234-244, 2009.

Cheng, Q., Agterberg, F. P., Ballantyne, S. B.: The separation of geochemical anomalies from background by fractal methods, J. Geochem. Explor., 51, 109-130, 1994.

Cheng, Q., Xu, Y., and Grunsky, E.: Integrated spatial and spectral analysis for geochemical anomaly separation, August 6-11, 6th Annual Conference of the International Association for Mathematical Geology, Trondheim, Norway, 1999.

Cheng, Q., Jing, L., and Panahi, A.: Principal component analysis with optimum order sample correlation coefficient for image enhancement, Int. J. Remote Sens., 27(16), 3387-3401, 2006.
Cheng, Q., Zhao, P., Zhang, S., Xia, Q., Chen, Z., Chen, J., Xu, D. and Wang, W.: Application of singularity in mineral deposit prediction in Gejiu district: Information integration and delineation of target areas, Earth Science, 34(1), 243-252, (in Chinese with English abstract), 2009.

Gan, F., Fang, W., Wang, X., Yang, S., and Zheng, H.: Ecology and environment, the heavy metal contamination in soil-potato and pea of tin tailings, 17(5), 1847-1852, (in Chinese with English Abstract), 2008.

Jung, M. C., Thornton, I., and Chonc, H. T.: Arsenic, Sb and Bi contamination of soils, plants, waters and sediments in the vicinity of the Dalsung $\mathrm{Cu}-\mathrm{W}$ mine in Korea, Science of the Total Environment, 295, 81-89, 2002.

Li, W., Li, L., and Yi, G.: Different data-processing methods for geochemical data from southern part of "Sanjiang (Three River)" region in south western China and their application results, Mineral Deposits 25(4), 501-510, (in Chinese with English Abstract), 2006

Lovejoy, S. and Schertzer, D.: Scaling and multifractal fields in the solid earth and topography, Nonlinear Processes of Geophysics, 14, 465-502, 2007.

Lovejoy, S., Agterberg, F., Carsteanu, A., et al.: Nonlinear Geophysics: Why we need it, EOS, 90(48), 455-456, 2009.

Meharg, A. A. and Maziburrahman, M. D.: Arsenic contamination of Bangladesh paddy field soils: Implications for rice contribution to Arsenic consumption, Environ. Sci. Technol., 37, 229234, 2003.

Pandey, P. K., Nair, S., Bhui, A., and Pandey, M.: Sediment contamination by arsenic in parts of central-east India and analytical studies on its mobilization, Current Science, 86(1), 190-197, 2004.

Qing, D., Tan, S., and Fab, Z.: Geotectonic evolution and tinploymetallic metallogenesis in Gejiu Dachang area, Acta Mineralogica Sinica, 24, 117-123, (in Chinese with English abstract), 2004.

Schertzer, D. and Lovejoy, S.: Generalised scale invariance in turbulent phenomens, Physico-Chemical Hydrodynamics Journal, 6, 623-635, 1985.

Schertzer, D. and Lovejoy, S.: Physical modeling and analysis of rain and clouds by anisotropic scaling of multiplicative processes, J. Geophys. Res., 92, 9693-9714, 1987.

Southwestern Metallurgy Exploration Company of the Ministry of Metallurgy Industry, Geology of Gejiu mineral district, Metallurgy Industry Press, Beijing, 1984.

Xie, S., Zhao, Y., and Xue, C.: Environmental issue and sustainable development in Gejiu, Yunnan, China, Population, Resources and Environment, 10(special issue), 89-90, (in Chinese), 2000.

Xie, X., Mu, X., and Ren, T.: Geochemical mapping in China, J. Geochem. Explor., 60, 99-113, 1997.

Yu, C., Tang, Y., Shi, P., and Deng, B.: The dynamic system of endogenic ore formation in Gejiu tin-polymetallic ore region, Yunnan Province. China University of Geosciences Press, Wuhan, China, 394 pp., (in Chinese with English Abstract), 1988.

Zhou, Y., Liu, J., Gao, Q., Han, H., Liu, D., and Zhang, C.: Utilization of regional geochemical data in living environment evaluation, J. of Earth Sciences and Environment, 28(4), 81-86 (in Chinese with English Abstract), 2006. 